\title{
GEOSSÍTIOS PONTUAIS ESSENCIAIS AO ENSINO DE GEOCIÊNCIAS NO RIO GRANDE DO SUL: CARACTERÍSTICAS E IMPORTÂNCIA PARA A GEOCONSERVAÇÃO
}

\begin{abstract}
André Weissheimer de Borba
Universidade Federal de Santa Maria, Centro de Ciências Naturais e Exatas, Departamento de Geociências (DEP-GEO/CCNE/UFSM), Av. Roraima, 1000, prédio 17, sl. 1131B, CEP 97.105-900, Camobi, Santa Maria/RS.awborba.geo@gmail.com

RESUMO: A geoconservação preocupa-se com a proteção, valorização, divulgação e uso sustentável do patrimônio geológico, que inclui desde grandes áreas complexas até geossítios isolados ou pontuais. Este trabalho focaliza cinco geossítios, de aproximadamente um hectare, situados em diferentes regiões do Rio Grande do Sul, desprovidos de qualquer atratividade turística ou destaque na paisagem, mas essenciais ao ensino de diferentes conceitos/processos em geociências: uma discordância angular, um pequeno pavimento glacial, um lajeado com estratificações cruzadas acanaladas de grande porte, uma dobra recumbente e um afloramento de arenitos triássicos com troncos fósseis. Tais geossítios, largamente utilizados para o ensino de estratigrafia e geologia histórica, foram analisados levando-se em conta seus atributos didáticos, condições de acesso e potenciais riscos a sua integridade e/ou visibilidade. Com base nas observações, sugerem-se medidas para sua proteção (tombamento legal, designação de buffer para silvicultura, eventual aquisição dos terrenos) e utilização racional e sustentável (implantação de trilhas/trapiches, sinalização informativa/educativa, indicação de acessos, divulgação às escolas municipais). Tais medidas poderiam partir das universidades gaúchas, sendo capazes de proporcionar impactos positivos na divulgação das geociências à sociedade e na maior integração do conhecimento geológico com a educação básica nos municípios onde tais geossítios se localizam.
\end{abstract}

Palavras-chave: patrimônio geológico, geoconservação, geossítios isolados.

ABSTRACT: ESSENTIAL POINT-TYPE GEOSITES FOR THE TEACHING OF GEOSCIENCES IN RIO GRANDE DO SUL STATE: CHARACTERISTICS AND RELEVANCE FOR GEOCONSERVATION. Geoconservation aims at the protection, valuing, divulgation and sustainable use of geological heritage sites, from large complex areas to point-type, isolated outcrops. This work focuses on five point-type geosites (area near 1 ha) from different regions of Rio Grande do Sul State (southernmost Brazil). The analyzed geosites display virtually no tourist attractiveness or landscape highlight, but they are essential for teaching a variety of geological concepts/processes: an angular unconformity, a small glacial pavement, didactic large-scale, eolian cross-strata, one recumbent fold and an outcrop containing Triassic fossil trunks. The referred geosites, extensively used for teaching stratigraphy and historical geology in southernmost Brazil, were assessed in their didactic and accessibility attributes, as well as in the associated risks to their integrity and/or visibility. Based upon the obtained data, a series of measures are suggested for the protection (legal protection, buffers for forestation projects, land buying) and sustainable use (trail design, informative signage, access indication, integration is basic school classes in the respective municipalities). Such measures could be initiated by Rio Grande do Sul State universities, being capable of becoming positive channels for geosciences popularization and integration of the geological knowledge in basic school teaching.

Keywords: geological heritage, geoconservation, point-type geosites.

\section{INTRODUÇÃO}

A geoconservação constitui, ao mesmo tempo, uma nova área das geociências (Henriques et al., 2011) e uma tendência de aproximação dos geocientistas com assuntos de interesse da sociedade, como a proteção ambiental, a educação básica e a gestão territorial. A geoconservação básica compreende todos os métodos para a identificação, inventariação e avaliação quantitativa de geossítios componentes do patrimônio geológico, ou seja, aqueles locais que melhor representam a evolução geológica de uma dada unidade territorial, que guardam da forma mais completa sua memória (geomemória). Por outro lado, as estratégias de proteção, valorização, divulgação e uso sustentável (para educação e turismo) desse patrimônio geológico fazem parte do que se convencionou chamar de geoconservação aplicada.

Diversos tipos de geossítios compõem o patrimônio geológico de diferentes unidades territoriais (Fuertes-Gutiérrez \& Fernandez-
Martinez, 2010): grandes áreas complexas e diversificadas, áreas mais homogêneas, seções lineares (no curso de rios ou ao longo de uma estrada) e afloramentos isolados, chamados também de geossítios pontuais (point-type geosites). Inegavelmente, os geossítios do tipo areal (area-type geosites, complex areas), com maiores dimensões em superfície, possuem 0 potencial de apresentarem maior atratividade para o turismo, além de maior geodiversidade e biodiversidade, tornando-se ideais e prioritários para a implantação de unidades de conservação e para estratégias do tipo 'geoparque'. Entretanto, a análise e a avaliação geopatrimonial de qualquer unidade territorial (UC, município, consórcio de municípios, estado, país) devem levar em consideração, também, geossítios pontuais (afloramentos isolados), muitas vezes sem qualquer atratividade turística ou beleza cênica, mas que constituem ferramentas didáticas essenciais para o ensino de processos ou conceitos fundamentais em geociências. 
Este trabalho apresenta cinco geossítios do tipo pontual (point-type geosites), ou seja, afloramentos isolados, localizados em diferentes regiões do Rio Grande do Sul, os quais ilustram de forma extremamente didática conceitos e processos das mais diversas áreas das geociências, especialmente da estratigrafia e da geologia histórica. Esses afloramentos, componentes (talvez desconhecidos, subestimados) do patrimônio geológico gaúcho, são avaliados aqui em seus aspectos geopatrimoniais, especialmente em termos de acesso, potencial didático e riscos à integridade, no sentido de propor iniciativas para sua geoconservação e aproveitamento didático mais efetivo e sustentável.

\section{DISCORDÂNCIA ANGULAR DO PIQUIRI, EM ENCRUZILHADA DO SUL - RS}

Um dos afloramentos mais didáticos para o ensino de conceitos fundamentais de estratigrafia no Rio Grande do Sul está localizado nas coordenadas $30^{\circ} 22^{\prime} 55^{\prime \prime} \mathrm{S}$, $52^{\circ} 50^{\prime} 02^{\prime \prime} \mathrm{W}$ em uma pequena coxilha (Fig. $1 \mathrm{~A}$ ), com menos de 20 metros de desnível no terreno, na localidade de Piquiri, zona rural de Encruzilhada do Sul ('metade sul' gaúcha). Situado à margem de uma estrada vicinal, de 'chão batido' (Fig. 1B), o geossítio apresenta, em sua porção inferior, camadas inclinadas (aproximadamente 45 graus) de arenitos e siltitos aluviais, de cor chocolate, vinculadas às unidades estratigráficas Mangueirão e Bom Jardim, do Neoproterozóico (600 a 580 Ma, Borba, 2006). Por sua vez, o terço superior da pequena elevação (Fig. 1C) é constituído por camadas sub-horizontais, de cor creme, de conglomerados fluviais, erosivos sobre a unidade inferior, com seixos e blocos de composição granítica dominante, atribuídos classicamente à unidade Itararé, do Permiano inferior (ca. $290 \mathrm{Ma}$ ). A coxilha, como um todo, oferece ao professor de geociências uma clara discordância angular (interpretação na Fig. 1A) com grande potencial didático: ali podem ser abordados aspectos de sedimentologia, basculamento tectônico das camadas inferiores, a dimensão temporal do hiato ali existente (300 Ma), bem como os próprios princípios estratigráficos da superposição e da horizontalidade original.
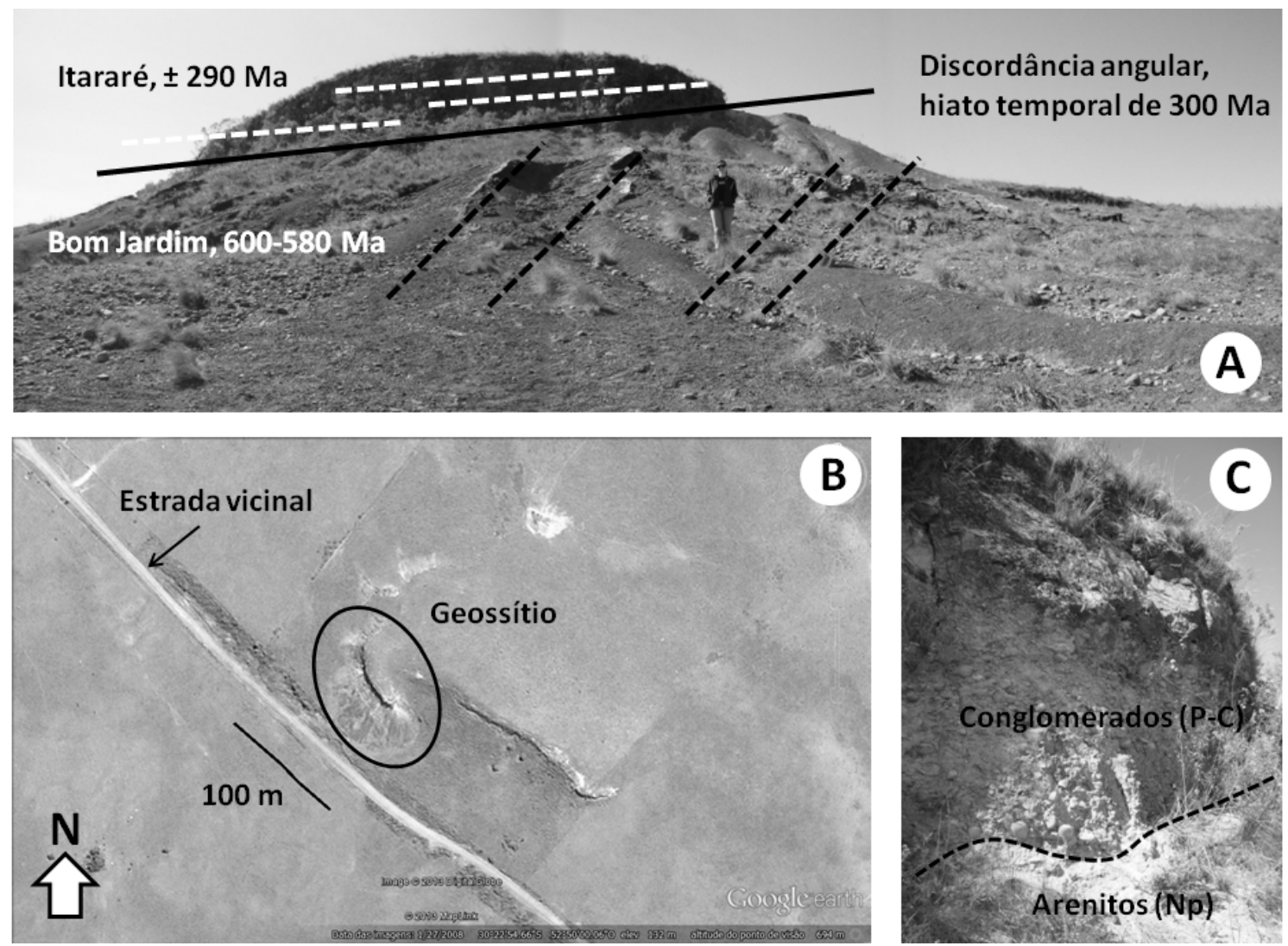

Figura 1 - características do geossítio da "discordância angular do Piquiri", em Encruzilhada do Sul (RS); (A) aspecto geral do geossítio e interpretação tectonoestratigráfica; (B) imagem extraída do GoogleEarth ${ }^{\circledR}$, para ilustrar as dimensões do afloramento; (C) detalhe dos conglomerados permocarboníferos em superfície erosiva sobre arenitos do Neoproterozoico. 
O afloramento em questão, no entanto, é vulnerável nos seguintes aspectos: (1) como todo o geossítio do tipo pontual, isolado, possui a priori uma vulnerabilidade intrínseca mais expressiva (Furtes-Gutiérrez \& Fernández-Martínez, 2010); (2) a elevação em que se encontra não possui qualquer tipo de proteção legal, nem mesmo como APP (área de preservação permanente) de 'topo de morro', pois o desnível de 15 metros não permite seu enquadramento legal como morro; (3) sua situação geográfica, junto a uma estrada vicinal, de "chão batido", pode ensejar sua degradação/destruição, por exemplo, na eventualidade de enxurradas e da necessidade de reparos na estrada, o que é fato corriqueiro no interior gaúcho; (4) a importância da feição é totalmente desconhecida por parte das autoridades municipais e da população do entorno, pois aquele local só é visitado por turmas de alunos de geologia e áreas afins, durante saídas a campo. Iniciativas de geoconservação, naquele local, deveriam envolver, no mínimo: (a) um alerta ao poder público municipal para a importância didática do local e para que não utilize aquela coxilha como área 'de empréstimo' de material cascalhoso; (b) uma declaração, por parte do poder público (Prefeitura e Câmara de Vereadores), daquela coxilha como uma unidade de conservação dentro do SNUC, a exemplo de um 'monumento natural' (MONA); (c) alternativamente, a aquisição de uma fração daquela gleba (hoje utilizada para pecuária de ovinos) por entidade interessada na conservação da natureza e do patrimônio geológico.

\section{PAVIMENTO GLACIAL DO IRAPUÁ, EM CACHOEIRA DO SUL - RS}

A evolução geológica da Bacia do Paraná no Rio Grande do Sul tem seu início marcado pela existência de geleiras vinculadas à glaciação do Permo-Carbonífero (e.g. Holz \& Carlucci, 2000). Um registro singular de tais eventos está situado no leito e nas margens de um afluente do arroio Irapuá $\left(30^{\circ} 26^{\prime} 15^{\prime \prime} \mathrm{S}, 53^{\circ} 05^{\prime} 35^{\prime \prime} \mathrm{W}\right)$, no interior do Município de Cachoeira do Sul. Trata-se de um pavimento de tilito estriado e sulcado por glaciares (Fig. 2A), identificado no início da década de 1980 (Tomazelli \& Soliani Jr., 1982) e, desde então, muito utilizado para aulas de campo sobre a geologia histórica do Rio Grande do Sul. Uma das feições mais interessantes e didáticas do afloramento é um bloco errático de quartzito que, empurrado pela geleira que o transportava, deixou atrás de si um sulco de dimensões métricas (Fig. 2B). As feições indicam um movimento da geleira no sentido norte. $O$ afloramento conta, ainda, com um adicional paisagístico, pois dali se podem observar duas coxilhas com a típica geomorfologia de "cuesta", diagnóstica da ocorrência de estratos sedimentares (Fig. 2C).
Constituindo um lajeado nas margens de um arroio, o pavimento glacial do Irapuá se enquadra como APP de 'margem de curso d'água', segundo o Código Florestal Brasileiro. Tal enquadramento não o protege, no entanto, de outros riscos, especialmente considerando que a região possui forte vocação para a silvicultura e a orizicultura (Cachoeira do Sul é a 'capital nacional do arroz'). Por exemplo, se não houver cuidados na bacia hidrográfica, na região a montante do geossítio, especialmente com relação ao uso do solo, pode ocorrer um aporte exagerado de sedimentos e o consequente assoreamento e ocultação do pavimento, com prejuízo a seu pleno aproveitamento educacional. A visibilidade das coxilhas em forma de "cuesta" também poderia ser comprometida, no caso da implantação de talhões de silvicultura entre o geossítio e a paisagem à sua volta. Nesse caso, recomenda-se a implantação de algum sistema de controle da sedimentação (canaletas e caixas de sedimentação) na estrada vicinal a montante do geossítio, que previna a ocorrência de processos de assoreamento, bem como o estabelecimento de um buffer para o plantio de espécies de árvores exóticas entre os geossítio e as coxilhas em forma de "cuesta", posicionadas a sudoeste. Melhorias no acesso (indicação de trilhas, instalação de trapiches), na sinalização (painéis informativos) e na comunicação com as escolas de educação básica do município poderiam também permitir um melhor aproveitamento deste geossítio como exemplo de um passado ainda mais gelado em Cachoeira do Sul e no Rio Grande do Sul.

\section{PALEODUNAS EÓLICAS DA BR-392, EM SANTANA DA BOA VISTA - RS}

A Formação Guaritas, do Paleozoico inferior (ca. $500 \mathrm{Ma}$, Borba 2006; Maraschin et al., 2010), registra um dos primeiros grandes desertos do supercontinente Gondwana, apresentando estratos aluviais, fluviais desconfinados e dunas eólicas de grande porte. A margem direita (sul) da BR-392, que liga Santa Maria ao porto de Rio Grande, no trecho do Município de Santana da Boa Vista, possui um afloramento $\left(30^{\circ} 44^{\prime} 18^{\prime \prime} \mathrm{S}, 53^{\circ} 12^{\prime} 07^{\prime \prime} \mathrm{W}\right)$ com substancial potencial didático. Consiste de um lajeado de quase um hectare, posicionado exatamente na margem da rodovia asfaltada (acessibilidade excelente), com estratificações cruzadas de grande porte, típicas de paleodunas eólicas, vistas em um ângulo que revela seu desenho em planta (Fig. 3A), situação perfeita para o ensino de paleocorrentes (medição \& interpretação do sentido do paleovento). Além disso, o mesmo conjunto de paleodunas possui uma exposição em perfil, a cerca de 150 metros de distância, em um corte da mesma rodovia (Fig. 3B), o que completa a visualização das estruturas sedimentares em três dimensões. 

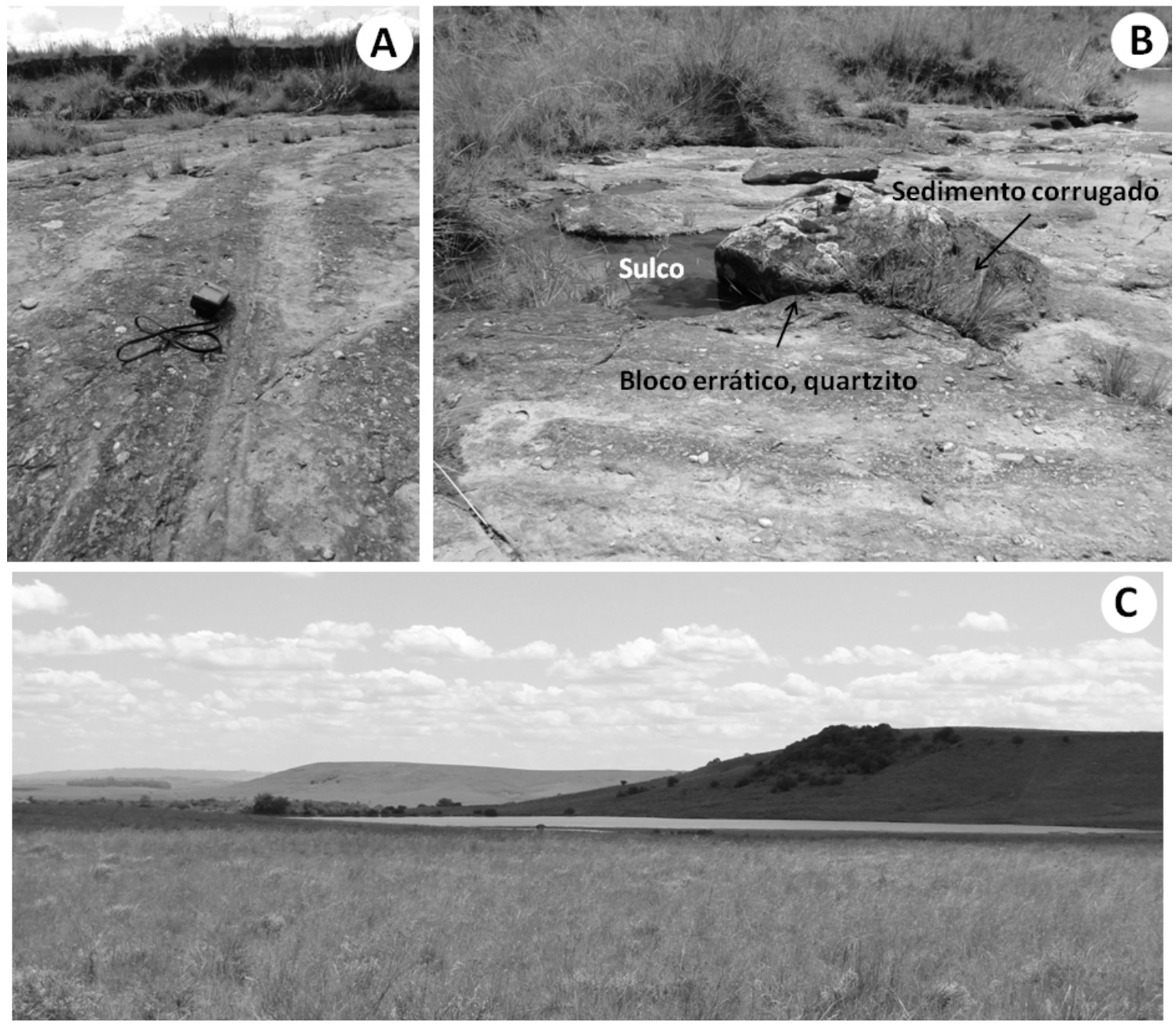

Figura 2 - características do geossítio do "pavimento glacial do Irapuá", em Cachoeira do Sul (RS): (A) sulcos produzidos por arraste glacial de fragmentos sobre tilitos (a escala é um aparelho de GPS, tanto em A quanto em B); (B) detalhe de um bloco errático de quartzito, com

sulco a montante e sedimentos corrugados a jusante, indicando transporte no sentido norte (para a direita na foto); (C) paisagem do entorno, visualizada desde o geossítio, com relevo típico de "cuestas", indicando a presença de rochas sedimentares dos estágios iniciais do Permiano da Bacia do Paraná no RS.
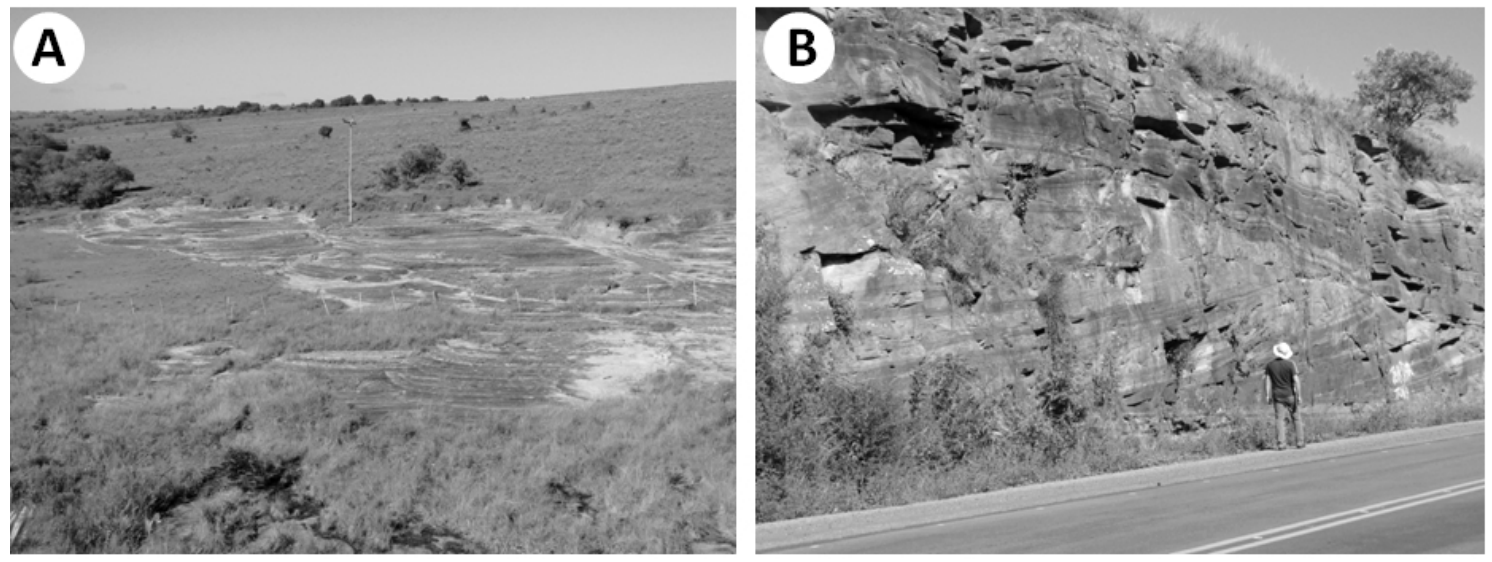

Figura 3 - características do geossítio das "paleodunas eólicas da BR-392", em Santana da Boa Vista (RS): (A) vista em planta das estratificações cruzadas de grande porte, ilustrando com perfeição o transporte é́lico no sentido sudoeste (para o canto superior direito da foto); (B) estratos cruzados de grande porte expostos em corte de estrada na mesma BR-392, a 150 metros do local da foto A, em que as cores avermelhada e amarelada dos foresets das dunas tornam sua exposição ainda mais didática e permitem sua visualização em três 
A coesão do maciço e as dimensões dos estratos cruzados the outorgam uma baixa vulnerabilidade. No entanto, é importante salientar que a rodovia possui um intenso tráfego de caminhões, que transportam a safra de grãos da região norte do Rio Grande do Sul (soja da 'região da produção') até o porto de Rio Grande. Assim, há riscos pessoais, especialmente quando o local é visitado por turmas numerosas, pois os estudantes têm de permanecer no acostamento desprotegido, observando as estruturas ao longe. Sugere-se contato e negociação com o DNIT ou a ANTT para a implantação de anteparos do tipo "guard-rail" e/ou até mesmo a construção de um 'mirador geodidático' mais seguro e espaçoso, que poderia também ter um painel interpretativo para o público em geral. Mesmo sem tais providências, sugere-se que o local seja manejado (para corte da vegetação que cresce próxima ao acostamento) com periodicidade mais frequente e que ali não sejam implantadas cortinas vegetais nem qualquer talhão de silvicultura.

\section{DOBRA RECUMBENTE NA BR-392, EM CAÇAPAVA DO SUL - RS}

A mesma rodovia BR-392, já no Município de Caçapava do Sul, apresenta um geossítio isolado com rochas metavulcânicas de composição intermediária e idade neoproterozóica, vinculado à unidade estratigráfica Passo Feio (Borba et al., in press). O geossítio situa-se $\left(30^{\circ} 24^{\prime} 05^{\prime \prime} \mathrm{S}, 53^{\circ} 30^{\prime} 01^{\prime \prime} \mathrm{W}\right)$ na margem da rodovia e constitui-se de uma dobra recumbente (Fig. 4A, 4B), feição largamente utilizada: (a) nas aulas de geologia geral, geologia histórica e estratigrafia, como evidência da ocorrência de zonas de cisalhamento e falhas de empurrão no Neoproterozóico do Escudo Sul-riograndense; e (b) nas aulas de geologia estrutural, como ponto de treinamento do trabalho prático com bússola para a medição das atitudes de eixo da dobra, plano axial e charneira, entre outros elementos da feição tectônica ali exposta.

Da mesma forma que o geossítio anterior, os riscos referem-se à integridade física de professores e estudantes, uma vez que o geossítio está em uma curva fechada da rodovia, em aclive, onde o acostamento é estreito e os caminhões trafegam muito próximos das paredes de rocha onde se posicionam os estudantes. Um agravante é o fato de que as melhores fotografias do geossítio são obtidas a partir da pista contrária, o que leva os profissionais e estudantes a cruzarem a rodovia de forma frequente. A situação ideal, naquele trecho, seria a limitação de velocidade, placas informativas sobre a possibilidade do trânsito de pedestres (estudantes) e a instalação de "guard-rail", uma vez que neste ponto não há recuo suficiente para alargar a rodovia sem danificar a feição geológica ali exposta. Uma observação importante é a possibilidade de que, estando este pequeno geossítio situado em um município que pode ser considerado a 'capital gaúcha da geodiversidade' (Borba, 2013), com grandes áreas complexas de forte apelo turístico/didático/esportivo/conservacionista (Guaritas, Serra do Segredo, Cerro da Angélica, etc.), sua importância relativa seja considerada menor e as medidas necessárias à manutenção da segurança dos estudantes sejam negligenciadas.
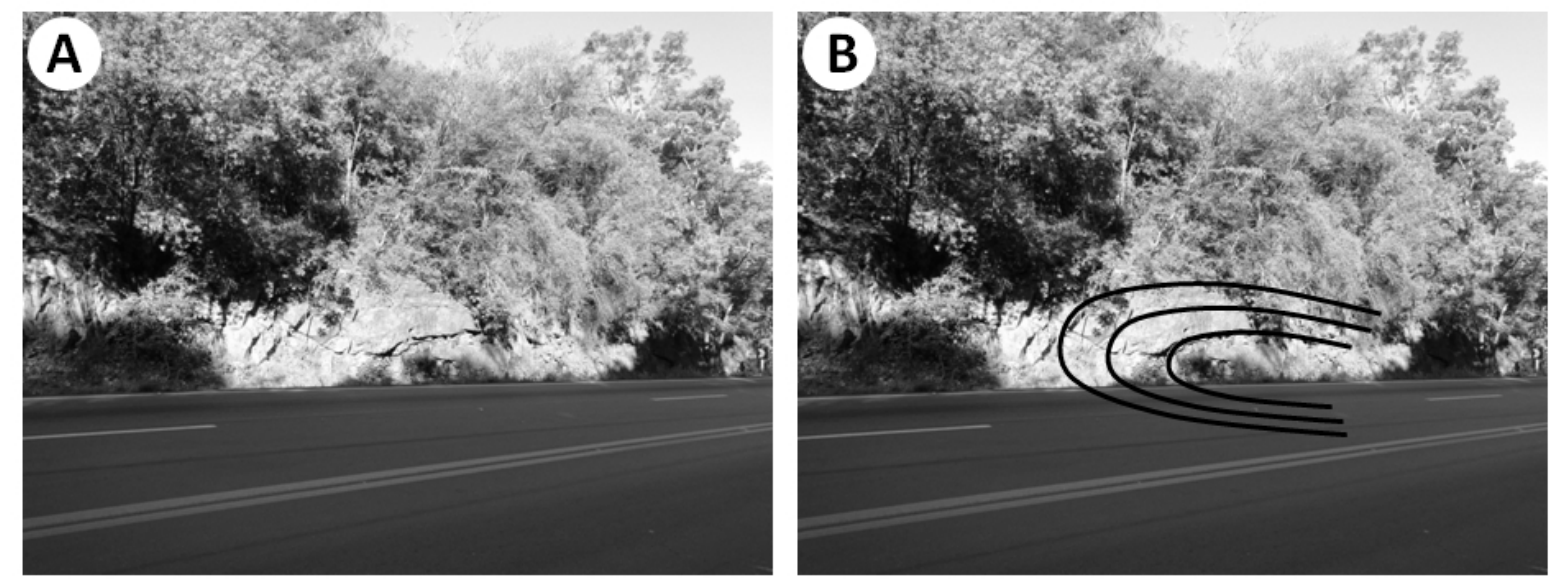

Figura 4 - Dobra recumbente desenvolvida sobre rochas metavulcânicas na BR-392, em Caçapava do Sul (RS), visualizada em fotografia sem interpretação (A) e com interpretação da feição estrutural, excelente para a prática de medições em geologia estrutural; no limite direito de ambas as fotografias, há uma placa indicativa da curva, para efeitos de escala. 


\section{TRONCOS FÓSSEIS NO 'SÍTIO DA PISCINA', NA RS- 287, EM SÃO PEDRO DO SUL -RS}

O período Triássico, na região central do Rio Grande do Sul, é caracterizado por três elementos principais: (1) as camadas vermelhas de arenitos e folhelhos de origem fluvial das unidades Passo das Tropas, Alemoa e Caturrita (Formação Santa Maria); (2) uma diversificada fauna de tetrápodes, incluindo alguns dos mais antigos dinossauros do Gondwana; e (3) a floresta petrificada de Mata e São Pedro do Sul, com troncos fósseis (de gingkos e coníferas) de dimensões impressionantes, silicificados no interior dos depósitos fluviais (Guerra-Sommer \& Scherer, 2002). A maior parte dos troncos fósseis foi retirada de seus locais originais, em uma iniciativa de permanência dos fósseis na comunidade, e adorna praças, igrejas e jardins paleontológicos nas cidades de Mata e São Pedro do Sul. Um dos poucos - e mais acessíveis - afloramentos de troncos fósseis in situ é o 'sítio da piscina' $\left(29^{\circ} 38^{\prime} 07^{\prime \prime} \mathrm{S}, 5^{\circ} 11^{\prime} 45^{\prime \prime} \mathrm{W}\right)$, às margens da rodovia asfaltada RS-287 (Fig. 5), que liga Santa Maria a São Borja, na fronteira oeste gaúcha.

Com relação a este geossítio, uma possível ameaça reside na eventualidade (remota) de uma duplicação da RS-287, que teria o potencial de destruir o afloramento, que é pequeno e delicado, e por isso vulnerável. Os pinheiros exóticos plantados no local (Fig. 5, esquerda) podem ser prejudiciais a fósseis que estejam em subsuperfície, se for considerada sua característica de possuírem uma raiz pivotante. O desconhecimento da importância do geossítio por parte tanto da população local quanto dos motoristas que trafegam pela rodovia, se não constitui uma ameaça direta, é uma comprovada subutilização do potencial da floresta petrificada de Mata e São Pedro do Sul como geomemória das paleopaisagens gaúchas. Assim, naquele local, poderiam ser igualmente implantadas placas de sinalização geoturística e um painel informativo com dados relevantes e curiosidades sobre esse capítulo interessante da evolução do Rio Grande do Sul.

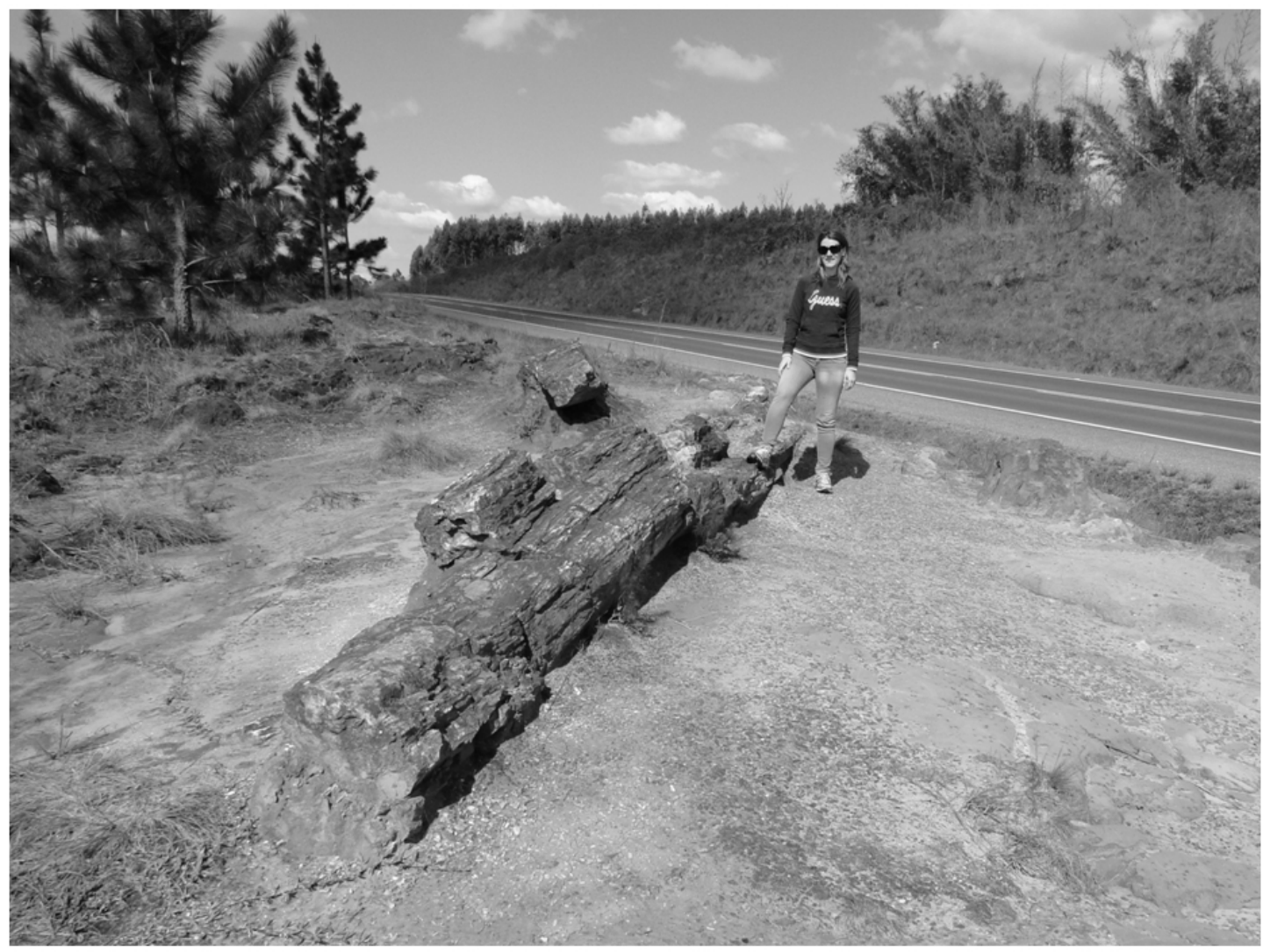

Figura 5 - Afloramento de troncos fósseis do Triássico no "sítio da piscina", às margens da RS-287, em São Pedro do Sul (RS); há troncos in situ, contidos no sedimento, não apenas na parte superior do afloramento, mas também no talude da rodovia; perceber a proximidade da rodovia e os pinheiros exóticos na porção esquerda da fotografia. 


\section{CONSIDERAÇÕES FINAIS}

A avaliação preliminar aqui realizada, focalizando cinco geossítios isolados (ou pontuais, point-type geosites) distribuídos pela 'metade sul' e região central do Rio Grande do Sul, permite algumas considerações sobre a pesquisa na área da geoconservação básica. Em primeiro lugar, salientase a necessidade de que geossítios pontuais sejam considerados e avaliados, e jamais negligenciados em avaliações geopatrimoniais ou estratégias de geoconservação, uma vez que seu valor educativo pode ser expressivo. Outra consideração diz respeito à complexidade da avaliação de riscos ou de vulnerabilidade de um geossítio, pois os fatores de risco são muito variáveis (erosão, assoreamento, obras civis, plantio de árvores que impeçam sua visualização, desconhecimento, etc.). Da mesma forma, a integridade e a segurança pessoal dos eventuais usuários dos geossítios isolados (professores e estudantes ligados às geociências) devem ser analisadas e incluídas entre as preocupações da avaliação geopatrimonial.

Com relação à geoconservação aplicada, pode-se observar que, diante da complexidade e da diversidade dos riscos e ameaças levantados, as iniciativas e ferramentas de proteção e uso sustentável dos geossítios também serão igualmente muito variadas, sendo definidas 'caso-a-caso'. A busca da proteção ou tombamento legal de geossítios através de figuras existentes na legislação florestal/ambiental (unidades de conservação do SNUC) é sempre indicada, mediante estudos específicos de tipologia e abrangência das UC. O cuidado com o patrimônio geológico deve ser considerado durante a execução de obras públicas, inclusive de reparação de estradas vicinais, ou de projetos privados (por exemplo, silvicultura). Sinalização, painéis informativos, melhoria de acessos e equipamentos de segurança são medidas bem-vindas aos casos estudados e à grande maioria dos bens geopatrimoniais em geral. Para a efetiva implementação das iniciativas aqui sugeridas, no entanto, é imprescindível que a comunidade geocientífica procure o poder público (prefeituras, governos estaduais, agências reguladoras, etc.), exponha a importância desses locais, esclareça a população sobre seu significado e invista nesse novo papel político de incentivar abertamente a geoconservação.

\section{REFERÊNCIAS BIBLIOGRÁFICAS}

Borba, A.W. 2006. Evolução geológica da "Bacia do Camaquã" (Neoproterozóico e Paleozóico inferior do Escudo Sul-riograndense, RS, Brasil): uma visão com base na integração de ferramentas de estratigrafia, petrografia e geologia isotópica. Tese de Doutorado, Programa de Pós-graduação em Geociências, Instituto de Geociências, Universidade Federal do Rio Grande do Sul, 110p + anexos.

Borba, A.W. 2013. Geoconservação em Caçapava do Sul (Escudo Sul-rio-grandense, RS, Brasil): ideias e sugestões com base em avaliação geopatrimonial. In: VIII Simpósio Sul-brasileiro de Geologia, Resumos, Porto Alegre, julho 2013.

Borba A.W., Souza L.F.; Mizusaki A.M.P., Almeida D.P.M., Stumpf P.P. (no prelo). Inventário e avaliação quantitativa de geossítios: exemplo de aplicação ao patrimônio geológico do Município de Caçapava do Sul (RS, Brasil). Pesquisas em Geociências, aceito para publicação (no prelo).

Fuertes-Gutiérrez I., Fernández-Martínez, E. 2010. Geosites inventory in the Leon Province (Northwestern Spain): a tool to introduce geoheritage into regional environmental management. Geoheritage, 2: 57-75.

Guerra-Sommer M. \& Scherer C.M.S. 2002. Sítios paleobotânicos do Arenito Mata (Mata e São Pedro do Sul), RS. In: Sítios Geológicos e Paleobiológicos do Brasil - SIGEP. Disponível em http://sigep.cprm.gov.br/sitio009/sitio009.pdf, acessado em $10 / 08 / 2013$

Henriques M.H., Pena dos Reis R., Brilha J.B.R., Mota T. 2011. Geoconservation as an emerging geoscience. Geoheritage, 3 (2), p. 117-128.

Holz M. \& Carlucci R. 2000. Litoestratigrafia, estratigrafia de seqüências e evolução paleofisiográfica da zona de borda da Bacia do Paraná no Rio Grande do Sul durante o EoPermiano. In: Holz M. \& De Ros L.F. (eds.) Geologia do Rio Grande do Sul. Porto Alegre, CIGO-UFRGS, p. 303-322.

Maraschin A.J., Mizusaki A.M.P., Zwingmann H., Borba A.W., Sbrissa G.F. 2010. Illite authigenesis in sandstones of the Guaritas Allogroup (Early Paleozoic): implications for depositional age, stratigraphy and evolution of the Camaquã Basin (Southern Brazil). Journal of South American Earth Sciences, 29: 400-411.

Tomazelli L.J. \& Soliani Jr. E. 1982. Evidências de atividade glacial no Paleozóico Superior do Rio Grande do Sul, Brasil. In: SBG, Congresso Brasileiro de Geologia, 32, Salvador, Anais..., 4:1378-1391.

Contribuição ao II Simpósio Brasileiro de Patrimônio Geológico

I Workshop Brasileiro de Patrimônio Geológico Construído 24 a 28 de setembro de 2013, Ouro Preto, MG. 